\title{
Prevalence of Celiac Disease in Children With Type 1 Diabetes Mellitus in Southeast Region of Turkey
}

\author{
Serap Yildirmaz ${ }^{\mathrm{a}}$, Derya Altay ${ }^{\mathrm{b}, \mathrm{d}}$, Ihsan Esen ${ }^{\mathrm{c}}$, Yasar Dogan ${ }^{\mathrm{b}}$
}

\begin{abstract}
Background: Although the relationship between celiac disease (CD) and type 1 diabetes mellitus (DM) is well recognized, there are no studies of this association in Southeast Region of our country. The aim of this study was to identify the prevalence of CD in a group of children with type 1 DM undergoing treatment in the Pediatric Endocrinology Department of our hospital.
\end{abstract}

Methods: The patients followed up with diagnosis of type $1 \mathrm{DM}$ in the Outpatient Clinics of Pediatric Endocrinology in our hospital were enrolled in the study. Anti-tissue transglutaminase (anti-tTG) IgA was measured in blood collected from these patients. Patients with anti-tTG IgA positive then had duodenal biopsy. Biopsy samples were obtained through an endoscopy procedure. Biopsy specimens were evaluated and classified according to Marsh classification.

Results: The study participants consisted of 218 patients (girls, $\mathrm{n}=$ 117: $53.7 \%$; boys, $\mathrm{n}=101: 46.3 \%$ ) with type $1 \mathrm{DM}$ with a mean age of $12.9 \pm 4.5$ years (range $2-18$ years). Sixteen patients had antitTG IgA positive. All of the cases with positive serology underwent duodenal biopsy. On histopathological evaluation, 11 patients had mucosal alterations compatible with celiac disease; five patients had non-specific histologic changes or normal biopsies. The prevalence of $\mathrm{CD}$ was $5 \%$ among 218 patients. Five cases with normal biopsy results were evaluated as having latent $\mathrm{CD}$.

Conclusions: These findings indicate that the prevalence of CD in children with type $1 \mathrm{DM}$ was higher than that in general population. Periodic screening of diabetic children and adolescents in terms of $\mathrm{CD}$ is indicated to ensure early diagnosis and treatment.

Keywords: Celiac disease; Childhood; Prevalence; Type 1 diabetes mellitus

Manuscript accepted for publication May 06, 2016

aDepartment of Pediatrics, Firat University Faculty of Medicine, Elazig, Turkey

bepartment of Pediatric Gastroenterology, Firat University Faculty of Medicine, Elazig, Turkey

'Department of Pediatric Endocrinology, Firat University Faculty of Medicine, Elazig, Turkey

${ }^{\mathrm{d} C}$ Corresponding Author: Derya Altay, Department of Pediatric Gastroenterology, Firat University Faculty of Medicine, Elazig, Turkey.

Email: dr.deryaaltay@gmail.com

doi: http://dx.doi.org/10.14740/ijcp239w

\section{Introduction}

Diabetes mellitus (DM) is one of the most frequently seen hormonal diseases in all age groups [1]. Celiac disease (CD) is an autoimmune enteropathy characterized by life-long hypersensitivity to gluten which affects the proximal intestine in genetically predisposed individuals subsequent to intake of foods containing gluten [2,3]. Chronic exposure to gluten can result in a higher incidence of autoimmune diseases such as hepatitis, autoimmune thyroid disease, connective tissue disease (Sjogren syndrome, rheumatoid arthritis), Addison's disease, and type 1 DM [4]. In patients with DM, autoimmune thyroid disease (about 15-30\%), CD (about 4-9\%), and Addison's disease (about $0.5 \%$ ) have been found, while 5-10\% of these patients have demonstrated endomysium IgA (EMA IgA) and tissue transglutaminase IgA (tTG IgA) positivity [5]. The prevalence of $\mathrm{CD}$ in patients with type $1 \mathrm{DM}$ is reportedly more than 20 -fold higher than that seen in the general population [6].

At the onset of diabetes, EMA IgA or anti-tTG IgA type antibody positivity is seen in nearly $60 \%$ of $\mathrm{CD}$ patients within type $1 \mathrm{DM}$. However, these cases are not routinely screened, and can therefore be missed to diagnosis. Antibody positivity in the remaining $40 \%$ of the cases mostly develops a few years after the onset of diabetes and even cases with asymptomatic, advanced stage type $1 \mathrm{DM}$ should be screened for CD [7]. The incidence of organ-specific autoantibodies in untreated patients with $\mathrm{CD}$ is higher than the predicted rates. In a prospective study of 90 known cases of $\mathrm{CD}$, diabetes-specific serum antibody positivity was seen in $11.1 \%$ [8]. Untreated CD in adults can lead to the development of complications such as osteoporosis and intestinal lymphoma, and at the same time impairment of glycemic control in patients with type $1 \mathrm{DM}$ $[9,10]$. The reason for the association between $\mathrm{CD}$ and type 1 DM stems from the sharing of common HLA genotypes (HLA DQ2 and DQ8), and accordingly they are frequently seen in combination [11]. The aim of this study was to determine the incidence of $\mathrm{CD}$ in children with type $1 \mathrm{DM}$.

\section{Materials and Methods}

Patients with type 1 DM followed up by the Pediatric Endocrinology Department of Firat University Hospital were enrolled in the study. Before starting, the study was approved by the ethics board of Firat University, and all families enrolled 
Table 1. Clinical Characteristics and Pathology Results of Diabetic Children Positive for tTG-lgA

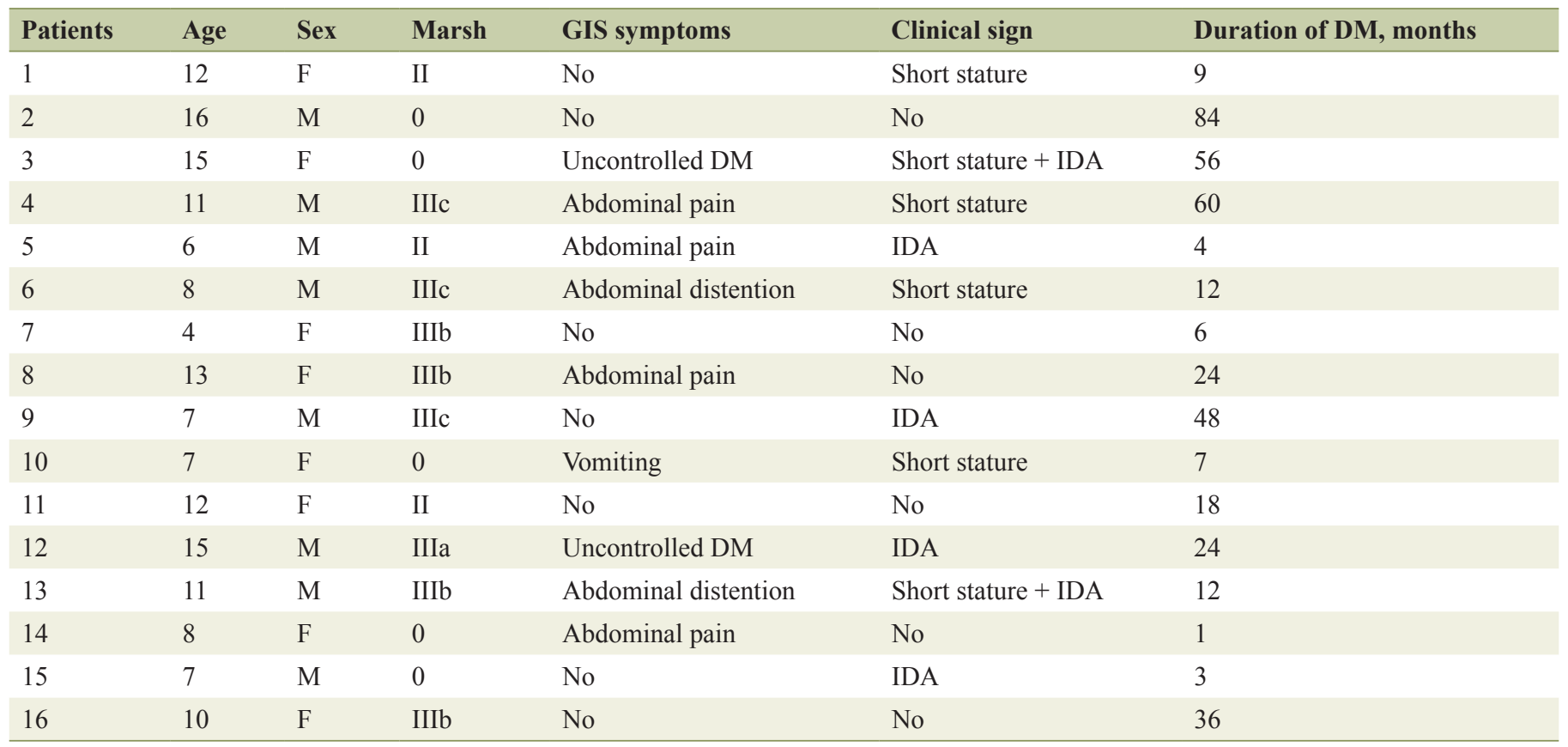

F: female; M: male; IDA: iron deficiency anemia.

in the study provided written informed consent. Serum samples were collected from all study participants. Three milliliters of venous blood samples were collected in laboratory tubes, left for coagulation and then centrifuged at 3,000 rpm for $3 \mathrm{~min}$. The separated serum fractions were stored in nongel tubes at $-80{ }^{\circ} \mathrm{C}$ until the time of analysis. Anti-tTG IgA (Seramun Diagnostica GmbH Serazy AntiTransglutaminase Kit, Germany) and IgA tests (enzyme-linked immunosorbent assay (ELISA) kit) were performed on the separated serum samples using different kits. Anti-tTG IgA antibody levels $>$ $20 \mathrm{Units} / \mathrm{mL}(\mathrm{U} / \mathrm{mL})$ were considered as positive results. Serum IgA was analyzed nephelometrically using Dade Behring Marburg GmbH N Antiserum Human Immunoglobulin Kits (Germany). In the second step, upper gastrointestinal tract endoscopy was performed in patients positive for the anti-tTG IgA antibody using a pediatric video endoscope (Olympus Evis Lucera CLV-260SL, Germany). The procedure was carried out after $6 \mathrm{~h}$ of fasting and under IV midazolam (0.1 $0.4 \mathrm{mg} / \mathrm{kg} / \mathrm{dose}$; max. $10 \mathrm{mg} /$ dose), pethidine hydrochloride 1 $\mathrm{mg} / \mathrm{kg} /$ dose ( $\max 75 \mathrm{mg}$ ) sedoanalgesia, and local pharyngeal anesthesia using 10\% xylocaine spray. During the endoscopy procedure, 2 - 3 pieces of intestinal biopsy specimens were retrieved from each patient. Biopsy materials were placed in formaldehyde solution and sent to the Pathology Department of Firat University Hospital. Pathological evaluation of the biopsy materials was performed by the same pathologist after staining with hematoxylin-eosin (H\&E). Leukocyte common antigen (LCA) immunohistochemistry was used for the evaluation of the intraepithelial lymphocyte count, and the presence of more than 30 intraepithelial lymphocytes versus 100 epithelial cells as detected by LCA was considered as intraepithelial lymphocytosis. The Marsh-Oberhuber scoring system was used for the identification of mucosal changes $[12,13]$.

\section{Results}

The study included 218 participants (girls, $\mathrm{n}=117: 53.7 \%$; boys, $\mathrm{n}=101: 46.3 \%$ ) with type $1 \mathrm{DM}$ with a mean age of $12.9 \pm 4.5$ years (range $2-18$ years). tTG IgA positivity was detected in $16(7.3 \%)$ of cases. None of the cases demonstrated IgA deficiency. Endoscopic intestinal biopsy was performed in those patients who were positive for anti-tTG IgA. In 11 $(5 \%)$ of these 16 cases, the biopsy results were consistent with CD. The 11 cases were staged as Marsh II $(n=3)$, IIIa $(n=1)$, IIIb $(n=4)$, and IIIc $(n=3)$. The five cases with normal biopsy results were evaluated as having latent CD and called for yearly follow-ups. In seven study participants, no gastrointestinal (GIS) symptoms were detected. In the remaining patients, abdominal pain and distension were the most frequently seen GIS symptoms, and short stature and iron deficiency anemia were the most frequently detected clinical findings. The clinical and laboratory characteristics of the patients are shown in Table 1.

\section{Discussion}

Serologic screening for CD is not recommended in CD patients with type $1 \mathrm{DM}$, as the clinical signs and symptoms (if any) specific to the CD are mostly mild [7, 9, 10, 14]. Moreover, the association between the time of onset of these two disease states and the timing of the emergence of CD after establish- 
ment of DM diagnosis is not known $[15,16]$. As the association between these two diseases is not yet fully elucidated, periodic serologic screening for $\mathrm{CD}$ is recommended in the initial and advanced stages of type 1 DM [7, 17, 18]. Based on previous studies, it has been asserted that one of the reasons for the higher incidence of $\mathrm{CD}$ in patients with type $1 \mathrm{DM}$ is that these diseases share common HLA genotypes. HLA genotypes carrying the highest risk for type $1 \mathrm{DM}$, that is, DQ2, and DQ8, are found in $90 \%$, and $8-10 \%$ of patients with $\mathrm{CD}$. Therefore, the association between these two disease states has been preferentially attributed to the mutually shared common genotype. Thirty-three percent of HLA DQ2 homozygous patients with type $1 \mathrm{DM}$ express CD-associated transglutaminase autoantibodies. However, CD-associated antibodies can be found in only $1 \%$ of HLA DQ2 and DQ8 negative patients with type 1 DM [11, 19]. Frohlich-Reiterer et al [20] reviewed the data of 41,951 patients with type 1 diabetes recruited from 297 centers in Austria and Germany between the years 1995 and 2009. Their results indicated a potentially higher incidence of $\mathrm{CD}$ in patients with type $1 \mathrm{DM}$ in the years to come.

Barera et al [7] detected a higher incidence (16.4\%) of serologic antibody positivity in patients with type $1 \mathrm{DM}$ while studies performed using tissue transglutaminase antibodies demonstrated serologic positivity ranging from $5 \%$ to $10 \%$. Moreover, a diagnosis of $\mathrm{CD}$ was established in approximately $75 \%$ of these patients $[11,19]$. In a similar study conducted in Turkey, tTG IgA positivity was noted in $13.5 \%$ of patients with type 1 diabetes [21]. In our study performed using anti-tTG IgA antibodies, we detected serologic positivity in 16 $(7.3 \%)$ out of 218 cases. In another study, Tanure et al [22] detected serologic positivity in $21(21 / 234 ; 8.9 \%), \mathrm{CD}$ in 10 $(10 / 234 ; 2.4 \%)$, and latent $\mathrm{CD}$ in nine $(9 / 234 ; 3.9 \%)$ of cases with type $1 \mathrm{DM}$, respectively. In some studies, the incidence of $\mathrm{CH}$ confirmed by biopsy has varied from $2.4 \%$ to $12.1 \%$ [21, 23]. Bhadada et al [24] found the mean incidence of $C D$ to be $11.1 \%$ based on tTG IgA analyses and the results of intestinal biopsies. In our study, CD was identified in $5 \%$ of the patients with type $1 \mathrm{DM}$. Half of patients with both type $1 \mathrm{DM}$ and CD had no GIS while mild GIS symptoms such as abdominal pain or distention were observed in the remaining half of the patients $[25,26]$. In

CD with type $1 \mathrm{DM}$, the most frequently observed clinical findings are short stature (52.3\%), and iron deficiency anemia $(47.3 \%)$, while the most commonly seen symptoms are weight loss $(42.8 \%)$, diarrhea $(28.6 \%)$, and abdominal pain (14.2\%) [24].

In our study, the most frequent clinical findings in patients diagnosed with $\mathrm{CD}$ were short stature and iron deficiency anemia, while the most common GIS symptoms detected were abdominal pain, distention, and vomiting. The frequencies of $\mathrm{CD}$, clinical signs, and symptoms identified in our study were consistent with the literature.

In conclusion, measurement of anti-tTG IgA in patients with type $1 \mathrm{DM}$ helped in the selection of suitable patient for duodenal biopsy. These findings indicate that the prevalence of $\mathrm{CD}$ in children with type $1 \mathrm{DM}$ is higher than that in the general population, and suggest that periodic screenings of diabetic children and adolescents is indicated to ensure early diagnosis and treatment of CD.

\section{References}

1. Kaczorowski J, Chambers LW, Dolovich L, Paterson JM, Karwalajtys T, Gierman T, Farrell B, et al. Improving cardiovascular health at population level: 39 community cluster randomised trial of Cardiovascular Health Awareness Program (CHAP). BMJ. 2011;342:d442.

2. Ciclitira PJ, King AL, Fraser JS. AGA technical review on Celiac Sprue. American Gastroenterological Association. Gastroenterology. 2001;120(6):1526-1540.

3. Garcia-Careaga M. Gluten-Sensitive Enteropathy (Celiac Disease, Celiac Sprue). Behrman R (editor). Nelson Textbook of Pediatrics. 17th ed: Saunders, 2004:1264-1266.

4. Book LS. Diagnosing celiac disease in 2002: who, why, and how? Pediatrics. 2002;109(5):952-954.

5. Barker JM. Clinical review: Type 1 diabetes-associated autoimmunity: natural history, genetic associations, and screening. J Clin Endocrinol Metab. 2006;91(4):12101217.

6. Collin P, Kaukinen K, Valimaki M, Salmi J. Endocrinological disorders and celiac disease. Endocr Rev. 2002;23(4):464-483.

7. Barera G, Bonfanti R, Viscardi M, Bazzigaluppi E, Calori G, Meschi F, Bianchi C, et al. Occurrence of celiac disease after onset of type 1 diabetes: a 6-year prospective longitudinal study. Pediatrics. 2002;109(5):833-838.

8. Miller LJ. Small intestinal manifestations of diabetes mellitus. Yale J Biol Med. 1983;56(3):189-193.

9. Andreelli F, Plotton I, Riou JP, Thivolet C. Diabetic instability and celiac disease. A frequent association to keep in mind. Diabetes Care. 1998;21(12):2192-2193.

10. Calero P, Ribes-Koninckx C, Albiach V, Carles C, Ferrer J. IgA antigliadin antibodies as a screening method for nonovert celiac disease in children with insulin-dependent diabetes mellitus. J Pediatr Gastroenterol Nutr. 1996;23(1):29-33.

11. Bao F, Yu L, Babu S, Wang T, Hoffenberg EJ, Rewers M, Eisenbarth GS. One third of HLA DQ2 homozygous patients with type 1 diabetes express celiac disease-associated transglutaminase autoantibodies. J Autoimmun. 1999;13(1):143-148.

12. Marsh MN. Gluten, major histocompatibility complex, and the small intestine. A molecular and immunobiologic approach to the spectrum of gluten sensitivity ('celiac sprue'). Gastroenterology. 1992;102(1):330-354.

13. Oberhuber G, Granditsch G, Vogelsang H. The histopathology of coeliac disease: time for a standardized report scheme for pathologists. Eur J Gastroenterol Hepatol. 1999;11(10):1185-1194.

14. Smith CM, Clarke CF, Porteous LE, Elsori H, Cameron DJ. Prevalence of coeliac disease and longitudinal follow-up of antigliadin antibody status in children and adolescents with type 1 diabetes mellitus. Pediatr Diabetes. 2000;1(4):199-203.

15. Vitoria JC, Castano L, Rica I, Bilbao JR, Arrieta A, GarciaMasdevall MD. Association of insulin-dependent diabetes mellitus and celiac disease: a study based on serologic markers. J Pediatr Gastroenterol Nutr. 1998;27(1):47-52. 
16. De Vitis I, Ghirlanda G, Gasbarrini G. Prevalence of coeliac disease in type I diabetes: a multicentre study. Acta Paediatr Suppl. 1996;412:56-57.

17. Cacciari E, Bianchi FB, Salardi S, Bazzoli F, De Franceschi L, Volta U. Late development of IgA antiendomysial antibodies and small intestinal mucosal atrophy after insulin dependent diabetes mellitus onset. Arch Dis Child. 1997;77(5):465.

18. Roldan MB, Barrio R, Roy G, Parra C, Alonso M, Yturriaga $R$, Camarero $C$. Diagnostic value of serological markers for celiac disease in diabetic children and adolescents. J Pediatr Endocrinol Metab. 1998;11(6):751-756.

19. Barker JM, Liu E. Celiac disease: pathophysiology, clinical manifestations, and associated autoimmune conditions. Adv Pediatr. 2008;55:349-365.

20. Frohlich-Reiterer EE, Kaspers S, Hofer S, Schober E, Kordonouri O, Pozza SB, Holl RW. Anthropometry, metabolic control, and follow-up in children and adolescents with type 1 diabetes mellitus and biopsy-proven celiac disease. J Pediatr. 2011;158(4):589-593 e582.

21. Ertekin V, Selimoglu MA, Doneray H, Orbak Z, Ozkan B. Prevalence of celiac disease in a sample of Turkish children and adolescents with type 1 diabetes mellitus. J
Clin Gastroenterol. 2006;40(7):655-657.

22. Tanure MG, Silva IN, Bahia M, Penna FJ. Prevalence of celiac disease in Brazilian children with type 1 diabetes mellitus. J Pediatr Gastroenterol Nutr. 2006;42(2):155159.

23. Aygun C, Uraz S, Damci T, Osar Z, Yumuk V, Akdenizli E, Ilkova H. Celiac disease in an adult Turkish population with type 1 diabetes mellitus. Dig Dis Sci. 2005;50(8):1462-1466.

24. Bhadada SK, Kochhar R, Bhansali A, Dutta U, Kumar PR, Poornachandra KS, Vaiphei K, et al. Prevalence and clinical profile of celiac disease in type 1 diabetes mellitus in north India. J Gastroenterol Hepatol. 2011;26(2):378381.

25. Kolho KL, Farkkila MA, Savilahti E. Undiagnosed coeliac disease is common in Finnish adults. Scand J Gastroenterol. 1998;33(12):1280-1283.

26. Kaukinen K, Salmi J, Lahtela J, Siljamaki-Ojansuu U, Koivisto AM, Oksa H, Collin P. No effect of glutenfree diet on the metabolic control of type 1 diabetes in patients with diabetes and celiac disease. Retrospective and controlled prospective survey. Diabetes Care. 1999;22(10):1747-1748. 